Draft paper: AOM 2017

\title{
Understanding the dual perspectives on workforce diversity in a British police service
}

\begin{abstract}
This paper explores how workforce diversity is understood and put into practice in the complex and dynamic work setting of the London Metropolitan Police Service (MPS). The analysis employs theoretical frameworks on diversity perspectives (Ely and Thomas 2001; Dass and Parker 1999) and diversity discourse (Janssens and Zanoni 2005; Litvin 1997; Zanoni and Janssens, 2007) in order to understand employee attitudes towards managing diversity, and to highlight the inherent context dependence of diversity effects in organizations (Joshi and Roh, 2009). The research provides empirical evidence of competing and dual perspectives among employees, which challenge the operational principles on diversity management in the MPS. The study evaluates ways in which the police service might leverage its organisational outcomes through developing context-based diversity management strategies.
\end{abstract}

\section{Keywords:}

Diversity, dual perspectives, police

\section{Introduction}

The composition of the UK's workforce has transformed over the last decades and, in dealing with this change, organizations across different sectors have adopted various strategies and perspectives on managing diversity. A limited number of studies have sought to understand the dynamics of managing diversity in public sector organisations (Greene and Kirton, 2009 and 2010; Kellough, 1990; Maxwell, 2004; McDougall, 1996; Pitts, 2005, 2007, 2009; Riccuuci, 2002). Much of the research on workforce diversity is set in private sector contexts, 
such as banks, ICT, law firms, retail, multinational corporations, and other private service organisations (Chatman et al., 1998; Dwyer et al. 2003; Foster and Harris, 2005; Jehn, Northcraft and Neale 1999; Richard 2000; Thomas 2001; Ely and Thomas 2001; Williams and O'Reilly 1998;), and most of these studies are largely positivistic, using quantitative measures to explore issues relating to diversity, particularly in the US literature (Chatman et al. 1998; Dwyer et al., 2003; Knouse and Dansby, 2000; O'Reilly et al., 1989; Pitts, 2009; Smith et al., 1994; Thomas and Ely, 2002; Williams and O'Reilly 1998). Public service organisations, such as the police service, have limited flexibility and innovation in their implementation and management of workforce diversity, due to their continued adherence to the merit system (Pitt, 2007). In addition, policing has its own patterns of authority relations and cultural due diligence, within a set of government legislations (Marenin, 1998). Together with its shared routines, values and intuitive occupational grasp, police officers also have an interpretive and active role in structuring their understanding of the organization and its distinctive work contexts (Chan, 2007).

The diversity literature abounds with advice about the advantages and disadvantages of having a diverse workforce. Scholars have actively promoted the 'business case' for diversity, mainly focusing on evaluating and explaining how diversity affects organisational performance outcomes (Cox and Blake, 1991; Cox, 1993; Childs, 2005; Dahlin et al., 2005; Hobman et al., 2004; Jehn et al. 1999; Kandola and Fullerton, 1994; McLeod, Lobel \& Cox, 1996; Mor Barak 2005; Schippers et al., 2003; Thomas, 1996; Van der Vegt \& Bunderson, 2005; Williams \& O’Reilly, 1998). Aside from the conceptual works and performancerelated analyses, there have been limited empirical studies on how to manage diversity while concomitantly ensuring employee support in different organisational contexts (Cavanaugh, 1997; Prasad, 1997; Ely and Thomas, 2001; Maxwell, Blair and McDougall, 2001; Pitts, 2009; Stephenson and Lewin, 1996; Janssens and Zanoni, 2005). 
Joshi and Roh (2009) call for a new agenda for diversity research, a debate that moves beyond the potential benefits or costs of diversity and instead highlights the inherent context dependence of diversity effects in organizations. They argue that a context-based approach to workplace diversity research can potentially provide practical insights that might enhance the effectiveness of diversity management practices. This study takes a context-based approach in examining diversity perspectives in the inimitable policing context in London.

Understanding how work groups make sense of their diversity is an important step in identifying how to effectively manage that workforce. The link between diversity strategy and practice is also impacted by the core values of the workforce and how effectively the broader strategies are operationalised in the various work contexts (Dass and Parker, 1999; Pitts, 2007). This research paper explores diversity perspectives of employees at various levels in the police service, thereby gaining insights on the complex interface of multiple identity dimensions in managing diversity in the varied contexts of police work.

\section{Understanding Diversity Perspectives}

A limited number of studies have focussed on what employees think about diversity and the possibility that the level of shared perspectives on diversity could influence work relations and performance outcomes in diverse work settings (Chen and Eastman, 1997; Dass and Parker, 1999; Ely and Thomas, 2001; Janssens and Zanoni, 2005; Kossek and Zonia, 1993; Mor Barak, Cherin and Berkman, 1998). These authors offer wide-ranging analyses on the issue of workforce diversity and conceptualise their findings in relation to the importance of diversity climate (Cox, 1991; McKay et al., 2007; Mor Barak, Cherin and Berkman, 1998), diversity discourse (Janssens and Zanoni, 2005; Tatli, 2011; Zanoni and Janssens, 2007), or diversity perspectives (Dass and Parker, 1999; Ely and Thomas, 2001) in organisations. Research suggests that when group members share common values and goals, diversity leads 
to more beneficial organisational outcomes (Cox and Blake, 1991; Ely and Thomas 2001; Mor Barak 2005, Morrison, 1992; Noon, 2007). What is of much significance in this research paper is to understand how employee perspectives on diversity, anchored in a specific work context, shape the organisation's approach to managing diversity.

Theories on diversity perspectives have typically illustrated the three or four stages of receptivity of an organisational climate for valuing diversity. In 1991, Taylor Cox put forward a framework on the monolithic, pluralistic, and multicultural organisation. Each of these organisations showed different approaches to the level of integration of minorities in the organisational culture and structure, different amounts of prejudice and bias, and varying frequency of intergroup conflict (Cox, 1991). This premise of typifying organisational values and practices in managing diversity was also adopted by Dass and Parker (1999) and Ely and Thomas (2001). Dass and Parker hypothesised a sequential movement across four diversity perspectives - resistance; discrimination-and-fairness; access-and-legitimacy; and learning in which each perspective improves on the inadequacies of its predecessor. Similarly, research by Ely and Thomas (2001) identified three diversity perspectives: the discrimination-and-fairness perspective, the access-and-legitimacy perspective, and the integration-and-learning perspective. This research paper builds upon their 1996 study to offer a social theory of how work groups make sense of their cultural diversity and how this shapes members identity, intergroup relations, and the conduct of work.

According to Ely and Thomas (2001: 234), the concept of diversity perspectives is characterised as the "governing rationale that guides people's efforts to create and respond to diversity in a work group, their expectations about the kind of impact, if any, those differences can and should have on the group and its work, and their beliefs about what constitutes progress towards the ideal multicultural work group". The discrimination-andfairness perspective is characterised by a belief in diversity as a moral imperative to ensure 
justice and fair treatment. It focuses on equal opportunities in hiring and promotion and uses diversity as evidence of just and fair treatment of employees. From this perspective, there is no instrumental link between diversity and the group's work activities. This perspective bears a close resemblance to the monolithic organisation on Cox's (1991) framework; the organisation is tolerant of minorities so long as they accept the dominant culture.

The second perspective in Ely and Thomas' framework is the access-and-legitimacy perspective. This view is based on the recognition that the markets and constituents of the organisation are culturally diverse and the organisation seeks to match that diversity as a way of gaining access to and legitimacy with those markets and constituent groups. Work groups with an access-and-legitimacy perspective do not incorporate the cultural competencies of the diverse workforce into core functions (Ely and Thomas, 2001: 243). This perspective bears close resemblance to the concept of a pluralistic organisation (Cox, 1991) which recognises the unique value that minorities offer, carefully selects workers as visible evidence of diversity, and yet still avoids changing the structure of the organisation.

The integration-and-learning perspective sees diversity as a resource for learning and adaptive change. Group functioning is seen to be enhanced by this perspective because it facilitates cross-cultural learning and constructive intergroup conflict. Therefore, the insights, skills and experiences of various cultural identity groups are valuable organisational resources (Ely and Thomas, 2001: 254). This perspective resembles the multicultural organisation in Cox's (1991) typology. A multicultural organisation values and fully incorporates minorities by modifying its structure and making any change necessary to take advantage of a diverse workforce.

By utilising demographic variables (race, ethnicity, sex, social class, religion, nationality, and sexual identity) which contribute to cultural identity, Ely and Thomas (2001) found mixed results based on different conditions and demographic composition of teams. 
They concluded that each perspective provides a rationale for why the work group should increase its diversity, yet only the third, the integration-and-learning perspective, was associated with what appeared to be sustainable performance gains attributable to diversity. Dass and Parker (1999) also concluded that a learning perspective could result in enhanced managerial control and argued, similar to Ely and Thomas (2001), that while equality measures are important as a starting point for increasing workforce diversity, they are not enough. It is argued that the major strength of the learning perspective is that it encourages the need to diversify work, rather than the people (Ely and Thomas, 2001; Dass and Parker, 1999). Both set of authors believe that diversity must be strategically linked to core organisational activities so that the alternative views can challenge normative assumptions about strategies and procedures which dominate the organisation's operation.

Lorbiecki (2001) warns that, even though the integration-and-learning perspective has the potential to develop a 'better' understanding of and value for diversity, it also has problems of political naivety. This is due to the fact that this perspective requires change to the core work processes and strategies, which could lead to political implications and organisational tension. Janssens and Zanoni (2005: 312) further criticise the theory-driven perspectives of Ely and Thomas (2001) pointing out that it still considers diversity as a set of given socio-demographic characteristics rather than as an organizational product embedded in organizational power relations. Understandably, diversity perspectives are not introduced to an organisation; they are perpetuated by its employees and agents of diversity who are also influenced by political and social processes both inside and outside of the organisation. It is therefore interesting to consider, in relation to the focus of this research paper, how employees perceive diversity and how their perspectives are influenced by the political and social tensions which may arise in the different police work contexts. 


\section{Methodology}

Some diversity researchers are of the view that methodological pluralism is more conducive to studying deeper structures of power and diversity when compared with purist methodologies of positivist or interpretivist tradition (e.g., Özbilgin et al. 2010). This research adopts a pragmatic mixed-methods approach that draws on multiple data sources for making careful abductive inferences. Following the principles of abduction, theory acts as an integral part of the methodology instead of being subordinate to the empirical findings. Therefore, in order to understand the dynamics of managing diversity, this research adopts critical methodological pluralism by incorporating a careful mix of deductive and inductive approaches.

Data was gathered with an aim to access the in-depth perspectives of the actors and agents of workforce diversity. This was generated through semi-structured interviews with 85 police officers and civilian staff, over a 6-month period. Non-participant observational fieldwork and documentary analysis were also carried out. Stratified sampling was used in order to account for various strands of diversity in the workforce. The research sample includes 85 subjects from a variety of races, ranks, a range of ages and lengths of service, and mix of genders. This multiplicity of interview participants facilitates multidimensional analyses of the experiences of different identity groups.

\begin{tabular}{|l|l|l|}
\hline Gender & $\begin{array}{l}\text { Number of } \\
\text { participants }\end{array}$ & $\%$ \\
\hline Male & 46 & $54 \%$ \\
\hline Female & 39 & $46 \%$ \\
\hline Total & $\mathbf{8 5}$ & \\
\hline
\end{tabular}

Table 1 - Gender profile of interview respondents 


\begin{tabular}{|l|l|}
\hline Age range & $\begin{array}{l}\text { Number of } \\
\text { participants }\end{array}$ \\
\hline & \\
\hline $20-29$ & 13 \\
\hline $30-39$ & 23 \\
\hline $40-49$ & 38 \\
\hline $50-59$ & 11 \\
\hline
\end{tabular}

Table 2 - Age profile of interview respondents

\begin{tabular}{|l|l|}
\hline Racio-ethnicity & $\begin{array}{l}\text { Number of } \\
\text { participants }\end{array}$ \\
\hline & \\
\hline White British & 54 \\
\hline White Other & 8 \\
\hline Asian & 7 \\
\hline Indian & 2 \\
\hline Black British & 7 \\
\hline Black African & 4 \\
\hline Mixed Other & 3 \\
\hline & \\
\hline
\end{tabular}

Table 3 - Racio-ethnic profile of interview respondents

\begin{tabular}{|l|l|}
\hline Length of Service & $\begin{array}{l}\text { Number of } \\
\text { participants }\end{array}$ \\
\hline 3-11 Months & 1 \\
\hline 1-2 years & 4 \\
\hline 3-5 years & 14 \\
\hline 6-9 years & 18 \\
\hline $10-15$ years & 9 \\
\hline $16-20$ & 15 \\
\hline $21-30$ years & 21 \\
\hline $31-37$ & 4 \\
\hline & \\
\hline
\end{tabular}

Table 4 - Profile of interview respondents' length of service 


\begin{tabular}{|l|l|l|l|}
\hline Rank & $\begin{array}{l}\text { Number of } \\
\text { participants }\end{array}$ & Staff band & $\begin{array}{l}\text { Number of } \\
\text { participants }\end{array}$ \\
\hline Chief Superintendent & 5 & Staff A & 2 \\
\hline Superintendent & 2 & Staff B & 4 \\
\hline Chief Inspector & 6 & Staff C & 5 \\
\hline Inspector & 9 & Staff D & 2 \\
\hline Sergeant & 15 & & \\
\hline PC & 26 & & \\
\hline PCSO & 9 & & \\
\hline
\end{tabular}

Table 5 - Rank profile of interview respondents

The interview participants were not asked to state their sexual orientation but during the discussions, four of the respondents stated that they were lesbians. Although disability was discussed with some respondents, none of the participants identified themselves as disabled.

The coding procedure developed by Strauss and Corbin (1990) was utilised with an aim to preserve the richness and meaning of the qualitative data. This involved reducing and abstracting the empirical data through open, axial and selective coding. The interpretations were refined using abductive reasoning to derive explanations for the diversity perspectives based on the causal powers of various structures and mechanisms identified within the organisation. Multiple data sources were employed for comparative analysis of key variables and relationships. This allowed the researcher to systematically explore multiple layers of the phenomena in order to abduce plausible explanations.

In an attempt to preserve the richness of the qualitative data, detailed empirical descriptions are presented. Alongside the detailed empirical descriptions, this paper employs abductive reasoning by drawing on other theoretical perspectives and secondary data in order to critically analyse the relationship between the identified perspectives, structures and mechanisms of diversity and inclusion in the police service. 
Although the analysis is primarily based on evidence from 85 semi-structured interviews, it also draws on data from field observations, statistical reports, official MPS documentation, reports and publications.

\section{Findings and Analysis}

The interview respondents were asked to share their viewpoints on the main value or benefit of having a diverse police service. Overarching themes that pervade the research data are examined in relation to relevant theoretical propositions. The literature suggests that there is a sequential movement across four diversity perspectives: resistance; discrimination-andfairness; access-and-legitimacy; and integration-and-learning (Dass and Parker 1999; Ely and Thomas 2001). The analysis does not seek to standardise or homogenise the perspectives and experiences of police officers but is concerned primarily with emphasising the nuanced but dominant narratives that emerged from the interview responses. At the selective coding stage, the responses were coded according to the categories presented in the diversity literature. Only categories that were explicitly identified in the empirical data are included in this analysis. Consequently, the resistance perspective is excluded as none of the interview respondents expressed such a viewpoint.

\section{Discrimination-and-Fairness Perspective in the MPS}

The discrimination-and-fairness perspective, which lays emphasis on the notion of justice and fair treatment, was mentioned by only eight (6) of the eighty-five (85) interview respondents. This viewpoint took on a reminiscent form rather than an active perception of current work conditions. This perspective was expressed by participants who had more than 15 years of service in the MPS and so had witnessed what they explained as external pressures to implement the Equal Employment Opportunities policy: 
"I consider the Met to be very much changed from when I joined. I consider it to be much more inclusive and much more positive, with people taking diversity much more serious than they have done. The trigger for that was the Lawrence Inquiry. I worked on the Lawrence Inquiry with Bob Quick and John Greaves when I was a sergeant back in 1999. I am aware of how that changed attitudes in the Met, quite brutally and over a short period of time." (Met033 - male, 41, Asian British)

Diversity management is arguably built on the legacy of equal opportunities (Cassell, 2001; Liff, 1996) and efforts to diversify the workforce were traditionally framed within the legal and moral imperative to promote justice and fairness at work. The interview respondents highlighted that the main focus of the MPS was on "equality in hiring" in order to comply with the Sex Discrimination Act (1975), the Race Relations Act (1976, amended in 2000), the Equal Pay Act (1979, amended in 1983), and later, the recommendations from the Macpherson Report (1999). Therefore, like most organisations, the MPS's original approach to diversity is considered to have been externally instigated and legally driven (Kandola and Fullerton, 1998).

On this viewpoint of equal employment practices, the respondents identified no links between workforce diversity and the work activities in the MPS. The interviewees expressed that even though there was a remarkable increase in the hiring of female recruits, this moral and legal measure did not protect them from the inequitable treatment that they faced once they had joined the organisation. A female officer recalled some of the prejudice that she faced during her early years in the MPS:

"I think things have improved a lot. Back then they were recruiting a lot of females. I can remember when I joined there were about 16 people and there were about 6 females which was quite a high proportion then compared to how many females were 
in the job. So at training school I felt I had a lot of female support around. However, when you get out onto teams there are much less females and you are dealing with officers with a lot more service. It gets difficult. It's harder because they automatically assume that you are not going to be as good as a man and they will actually tell you that. We used to get called 'PLONKS'- 'Person with Little Or No Knowledge'. It was normally said in a humorous way but it was a word that was used a lot, particularly by the older males when describing female officers." (Met025 female, 43, White British)

Some of the early experiences of female officers plainly demonstrate the principle of neutrality that underpinned the 'sameness of treatment' of the equality framework (Lorbiecki and Jack, 2000). The experience of Met025 was echoed by several senior-ranked female respondents who spoke of other pejorative terms that were used to describe them during their early years as police officers. Their experiences illustrate the lack of tolerance that is associated with a discrimination-and-fairness perspective. This diversity perspective, although not the current or prominent perspective of the respondents, can be interpreted as a predecessor of the current diversity perspectives held in The MPS. This corresponds with the general view that diversity builds on the legacy of equal employment opportunity (Cassell, 2001; Liff, 1999) and each diversity perspective improves on the inadequacies of its predecessor (Cox, 1991; Dass and Parker 1999; Ely and Thomas 2001).

\section{Access-and-Legitimacy Perspective in the MPS}

Access-and-legitimacy was the most prevalent perspective among the interview participants, with 69 of the 85 respondents (81\%) identifying the need for the MPS to be more visibly representative of its diverse communities in order to offer "better service" to the public: 
"I think the value of it is pretty simple, really, and that is, without it [workforce diversity] we can't police by consent and that is a fundamental principle on which policing across the civilised world is built on. Unless you are in a dictatorship, we police by consent. If we are not reflective of the community that we serve then there has to be a gap in how effective we are and how the community perceives us. So for me, it is a fundamental principle that we reflect our community." (Met015 - male, 45, White British)

The practical and operational benefits of diversity were proclaimed by interviewees from all ranks and all backgrounds. A senior-ranked officer provided examples of how she had observed workforce diversity engender better communication and interaction with different groups in her constituency:

"I think we've got to be reflective of the community we serve. And again, cheesy but truthful. There have been some moments when I've seen some of my PCSOs, the one I'm talking about is an Italian speaking Nigerian, who just chats away with certain people in the street because they identify with him for those two reasons - language and culture. He's got a very strong Nigerian accent and just to see that engagement is heart-warming. I've only had about 3 of these moments in the job where I just stop and think 'wow this is excellent'. Another incident last week, I went downstairs and one of the station PCSOs who is relatively new, he is quite nervous, quite quiet. He was over the moon that he was taking a CRIS report in some sort of native tongue; I can't remember which language it was, some kind of Somalia type. The woman who was reporting was just overwhelmed that the officer spoke her native tongue and made it so much easier for her to give her report. I think that's what diversity is about 
and if people can't see the value in that, then it's such a shame." (Met013 - female, 38, White British)

The general arguments and examples given by the interview respondents are consistent with the theories of Ely and Thomas (2001) and Dass and Parker (1999) which characterise the access-and-legitimacy perspective as valuing diversity as a resource only at the interface between the organisation and its market/clients. Berg (1999) also found that the role for ethnic minorities in the police remained restricted among the lower ranks where their natural cultural links to the community would re-establish both the police role and image in specific communities. The interview respondents in this study similarly highlighted the importance of having a wider representation of female and BME officers at the lower ranks for the purpose of improved interaction with the community:

“There's a large number of ethnic officers in the Met, most of them are PCSOs, less are PCs and a few are sergeants and so on. I think the distribution at other ranks could be better but, right now, we are doing something good because PCSOs are closest to the communities in terms of visibility and interaction. A lot of PCSO's are well educated because they come into the Met as mature students. I think the mix is very balanced at that level and that's good for the variety of work we have to do in communities." (Met069 - female, 34, Black African)

The access-and-legitimacy perspective prevailed as the primary rationale for diversifying the demographic composition of the police service simply because it ensures "greater public confidence". The interview respondents asserted that public confidence is crucial, and also quite instrumental in helping them do their job better. This, they stressed, is not simply about being legitimate to those diverse communities, but about gaining deeper 
access and better engagement with the people. This notion of 'access' was that of genuine cooperation from the community which enabled better intelligence gathering and quicker crime solving for the police. Senior-ranked officers tended to draw comparisons between prior and current experiences of policing BME communities and one such officer illustrated an instance where crime prevention was more successful because of enhanced community engagement:

"In the run up to Diwali, this is the Indian festival of lights, similar to Christmas; in the run up to Diwali we get a rise in residential burglaries where the victims are Indian. They get their gold out of the bank to celebrate the festival; they leave the gold at home and their house gets burgled. Police intelligence picks up this pattern and we try to get into the temples to educate the people, including my own mother who took her gold out the bank and left it in her home. Access to the temples is crucial; we used the Hindu Association and our BME officers to address this. Like it or not, some people are intimidated by the police and so using ethnic officers helped to make them less suspicious of the police's intentions. They give the presentations in Guajarati, Hindi and any language that makes it easier for these people to understand the issues. We also ask people with information to come forward; the response was tremendous. These people would never have phoned up Crime Stoppers to give information but they are confident talking to officers they believe will understand them. That's how the Met uses diversity for intelligence led policing." (Met078 male, 34, Asian British)

While the majority of the respondents highlighted the importance of BME officers in providing effective policing, some officers called attention to the general image of the police service. They argued that the MPS needed more than female and BME quotas to change 
public perception of the police. Met013, at the end of her statement about the levels of 'access', also made reference to the police uniform being a source of access and legitimacy. The notion of legitimacy in the literature refers to the authenticity of shared identity and/or cultural understanding which affords an organisation the desired social acceptance. Legitimacy, in this sense, is unrelated to the rational-legal authority of the police which does not guarantee genuine access to people (Berg 1999; Young, 1991).

Police officers spoke about the challenge of being viewed as the stereotypical 'bobby' by people in certain communities. While BME officers often found it easier to interact with specific ethnic groups, they also admitted that the police image sometimes overshadowed their own cultural identity:

"There is no respect for my uniform; it's more of a grudging acceptance from some of our communities." (MET008 - male, 46, White British)

"For some officers the uniform makes them feel invincible. You become 'the law'. It's like they transform to a new person. The uniform doesn't help me; the uniform is the worse. People talk to you easier when you are not in uniform. Still, a lot more Asian people will speak to me about their problems because I am Asian. I can see why this would happen on street because they want an officer they can relate to." (MET083 - male, 22, Indian British)

A female LGBT officer also spoke about the challenge of getting people to see past the police uniform. She indicated that people are disinclined to see past the police guise but once they realise that there is "someone behind the uniform" they become more responsive: "Having BME officers help. I was out patrolling with a female Sri Lankan and there were some youths mouthing off in their language and she suddenly talked back to 
them. They were shocked because they didn't realise she could speak their language; all they saw was the uniform. They never see past that. Afterwards they just chilled out and she talked to them and everything was good. These things help, that's why I wear my LGBT badge hoping that the rainbow flag will catch people's eyes and they will see that there is actually someone behind the uniform. In the past the gay community hadn't been treated well and there was a lot of fear of reporting anything to the police. I just hope that people will see from my LGBT badge that their issues will be treated sensitively. And there is a language barrier, for example, an ordinary male officer might not get what they mean when someone says they wear costumes. They would probably miss the point." (MET021 - female, 37, White British)

The empirical evidence illustrates a widely held perception that the MPS will improve its level of access and legitimacy in communities if the organisation reflects the diversity of the different communities it serves. Whilst this viewpoint suggests a strong police ethos for the access-and-legitimacy perspective, the diversity literature conversely proposes that organisations should pursue an integration-and-learning perspective because this approach will reduce the negative consequences of diversity and further enhance organisational performance.

\section{Integration-and-Learning Perspective in the MPS}

The integration-and-learning perspective, in its strictest form, is concerned with diversifying the practice of work and challenging normative assumptions about the organisation's strategies and core activities. The respondents who expressed this perspective deliberately linked the value of workforce diversity to the insights, skills development and social 
experiences that police officers are able to gain as a result of working with people from diverse backgrounds.

A quantitative illustration (figure 1) shows that only 13 (15\%) of the 85 interview respondents exclusively held an integration-and-learning perspective, while 37 (44\%) expressed an access-and-legitimacy perspectives, and 3 respondents said that they did not view diversity as having any impact on policing (these participants are classified as 'neutral'). The remaining 32 respondents $(38 \%)$ expressed dual perspectives. So, $38 \%$ of the participants identified both the access-and-legitimacy as well as the integration-and-learning perspectives when explaining the value of workforce diversity. Therefore, a combined total of 45 respondents (52\%) expressed an integration-and-learning perspective for diversity.

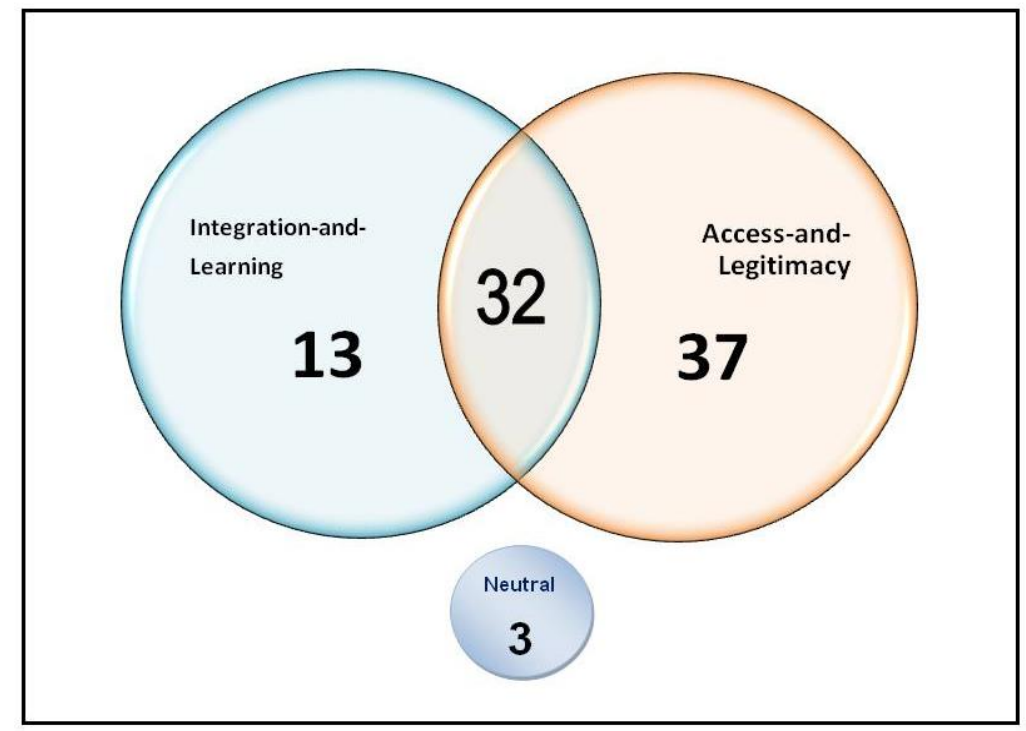

Figure 1 - Diversity perspectives of the interview respondents

Although the integration-and-learning perspective was not the most prominent perspective among the interview respondents, there were patterns in the empirical data which illustrate some factors and conditions that shape these differences in diversity perspectives. The integration-and-learning perspective was strongest amongst respondents who had less 
than 10 years' service, with $62 \%$ of these respondents identifying integration and learning as important benefits of workforce diversity:

"In this job, it is very helpful to have colleagues from complete different backgrounds who can share their knowledge and experiences. London is a big city and is as diverse as it can get. Whatever happens outside, we always discuss it in the office so that next time a member of the team has to deal with something similar, regardless of their own background and experiences, they will have a pretty good idea what to do based on the experience of others." (MET036 - female, 46, Russian)

From the sample of BME respondents, $71 \%$ expressed an integration-and-learning perspective. Gender difference appeared to be inconsequential with 53\% of female and 52\% of male respondents expressing an integration-and-learning perspective. In terms of age, $69 \%$ of participants aged 20-29 highlighted an integration-and-learning perspective as the main value of having a diverse workforce. Education also presented a possible variable for diversity perspectives with $48 \%$ of participants with higher education qualification expressing an integration-and-learning perspective. It is worth noting that the majority of the respondents with undergraduate qualifications were young and lower-ranked police officers.

Diversity perspectives were also consistent among officers at the same rank or those who shared similar job roles and functional backgrounds. The integration-and-learning perspective was expressed by $78 \%$ of PCSOs and $56 \%$ of respondents who worked on safer neighbourhood teams (SNT). These groups of officers have a high degree of interaction with the community as well as with their work colleagues. These smaller teams also facilitate an integration-and-learning perspective possibly because of the higher frequency of interaction in a more cohesive environment, which makes it easier for diversity to influence social processes within such group context (Cavanaugh, 1997; Prasad, 1997; Jehn et al. 1999; Pelled 
et al. 1999). For example, an SNT officer spoke about the level of sharing and integration that is casually experienced on her team and illustrated how it helps officers in their work performance:

"You tend to get to know the people you work with. We all work in one office; there are two teams and we police the same area. When someone is not around we can deal with their cases because we all talk about what is happening so we are all familiar with what's going on. All the calls come into the same office and we answer each other's call. Someone would, for instance, come off the phone after speaking with a Polish woman and comment about how rude the woman was on the phone. Through that open discussion, there's a Polish female officer on our team so we would explain that we've also spoken to the same woman and she is actually not rude; it's just a manner of speaking. It sounds rude to others because it's a different structure of the language; we do not use 'please' and 'thank you' as much in our language. So people can wrongly assume that someone isn't polite or nice because of they use the language a bit differently." (Met036 - female, 46, Russian)

From the sample of respondents below the rank of Sergeant or staff band D, 67\% expressed an integration-and-learning perspective, while only $30 \%$ of senior-ranked officers and staff perceived such value from workforce diversity. (Insert stats for BME at senior level of MPS). There was also evidence that individual perspectives are influenced by their social background. Officers from homogeneous backgrounds generally expressed an access-andlegitimacy perspective; only $33 \%$ of such respondents expressed an integration-and-learning perspective on diversity. Interestingly, $63 \%$ of respondents who expressed an integration-andlearning perspective were from heterogeneous backgrounds. Many of whom were born and bred in London or grew up in a multicultural environment. What was more interesting about 
these respondents was that, even though they expressed an integration-and-learning perspective, they also viewed diversity as "nothing special" because it was considered a normal part of their lives.

Other 'Londoners' expressed parallel viewpoints that their level of familiarity with people from diverse backgrounds made it a commonsensical part of their job. In contrast, the few respondents from homogeneous backgrounds who expressed an integration-and-learning perspective spoke of their unfamiliarity with the demography of London and emphasised the importance of learning from their work colleagues:

"In terms of diversity, I was certainly thrown into the deep end. I worked in a borough that has the largest Asian community in Europe. You needed an interpreter almost all the time or a support staff who understood that environment. It was interesting working in that area. I've found the same problems working in other boroughs but at least I could learn from my colleagues' experiences and knowledge. For instance, investigating domestic violence in any Asian community is very difficult because there is a cultural stigma attached to it; it's considered that it should be kept within the family. I was out taking a statement from a victim using an interpreter and there was a uniformed officer there who spoke Bengali and he took me aside and said that our interpreter was telling the victim not to dishonour her family by giving evidence to the police. These interpreters are vetted through the Home Office but they still have no allegiance to the Met. Having minority ethnic officers with the language skills is very important for us to do our job better. I've also benefited from the wide experiences and different points of view of people on my team. Therefore, the more diverse the police service, the more resources we have to draw on." (Met011 - male, 29, White British) 
The evidence suggests that a higher level of familiarity with diversity has had a positive influence on the espousal of an integration-and-learning perspective on workforce diversity. This supports arguments in the diversity literature that the sociocultural context and makeup of workforce determines the discourse of diversity in the work place (Cavanaugh, 1997; Prasad, 1997; Janssens and Zanoni, 2005; Johns, 2004).

\section{Dual Diversity Perspective}

The analysis reveals a hybrid or dual perspectives on diversity, an indication that the MPS is somehow wedged in transition between the access-and-legitimacy perspective and the integration-and-learning perspective. The external market orientation of the police service gives prominence to the access-and-legitimacy perspective yet a significant number of respondents also spoke about the importance of learning from each other's cultural competencies in order to improve the work of the MPS:

“I think it's absolutely vital. We still talk about policing by consent where we've got the public on our side. Also, with the ever-changing population of London where you are dealing with people from diverse cultural backgrounds, I wouldn't have any understanding of their needs or individual requirements. Okay, I could read a book but it doesn't give you the same information. So it's absolutely vital to have a mixed workforce that reflects as much as possible who we are dealing with. Females and minority officer also bring vital skills to the service which everyone can learn from.” (Met001 - female, 38, White British)

While the access-and-legitimacy is the most popular perspective in the MPS, the numbers in figure 1 indicate that a transitional process is in effect. The intersection shows 32 respondents who are torn between the two perspectives (access-and-legitimacy and 
integration-and-learning); however, the analysis suggests that this overlap is not just a transition through a theorised sequence of diversity perspectives but instead is an atypical development of a twofold perspective on workforce diversity. The interviewees emphasized persistently that the success of the MPS was dependent on its public image, not only through increased numbers of female and BME officers but also through a greater perception of tolerance and cultural understanding. Their fundamental view was that diversity should be utilised to engender better engagement with the community. This enduring external orientation of police officers and staff, arguably, delays the organisation's full progression to the 'integration-and-learning' perspective.

The dual perspective takes values from the final two stages of the diversity perspectives continuum. The respondents who argue for the twofold value of diversity have created a new 'access-and-learning' perspective which puts emphasis on different elements of the original perspectives that were used to categorise the data. This dichotomy is grounded in the unique police work contexts. For instance, the 'integration' element of the integration-andlearning perspective was less prominent among respondents who worked on large territorial response teams. The value of integration was mainly expressed by respondents who worked on smaller safer neighbourhood teams (SNT) which had high levels of community interaction:

"The level of diversity on teams varies; my team is fairly diverse but other less diverse teams don't get a chance to integrate with us because they are on different shifts. There is a brief 1-hour cross-over time between shifts but you still won't get a lot of meaningful interaction then. Smaller teams such as Safer Neighbourhood Teams can integrate more because they have better schedules. Response teams, on the other hand, are large and sort of isolated because of the shift structure. You could easily 
work on a borough with a vast pool of skills and not know what they are." (Met023 male, 31, Asian/Pakistani)

The dichotomy of the integration-and-learning perspective becomes quite obvious when respondents from the larger territorial response teams (Territorial Support Group) bluntly downplayed the value of integration and social learning. Some declare that social integration is insignificant because officers can acquire relevant knowledge and skills though centralised resources:

"The Met is not big on socialising per se while at work. Integration is usually at the association level, we have cultural groups that organise meetings and activities. Teams will go out for beers after work but you won't hear people discussing cultural differences there; we have a skills database at work for that! ” (Met019 - male, 49, White British)

Territorial response teams account for a large segment of the police workforce. These teams comprise officers with a specific mix of skill levels and competences, based on formal police training. Gender and racio-ethnicity were rarely considered essential factors for the makeup of response teams. Workforce diversity was valued mainly for practical purposes such as stop-and-search of female civilians by a female officer or in special situations where language or cultural barriers were broken by BME officers to enhance policing effectiveness. These findings echo the results from other studies which positively linked task-related and information-related diversity dimensions to work group performance and openness to diversity (Chou et al., 2004; Horwitz and Horwitz, 2007; Jehn et al., 1999; Pelled et al., 1999). Respondents from these teams spoke about formal channels such as the Cultures Communities Resource Unit (CCRU) which is "utilised throughout the MPS as a diversity 
resource for teams that might not have Eastern European officers or other BME officers on their teams" (Met004). This approach tend to result in a lack of cross-cultural learning (Cox, 1991; Ely and Thomas, 2001).

There are clear indications of a thriving integration-and-learning perspective in some parts of the MPS but somehow it has not managed to filter through the espoused tenets of some other core groups within the organisation. The key factor appears to be that of social work context in which integration and social learning is facilitated (Cavanaugh, 1997; Prasad, 1997; Janssens and Zanoni, 2005; Johns 2004). The context of work in small groups (such as SNT) seems to facilitate the mechanisms for an integration-and-learning perspective, but such mechanisms are quite limited in the work context of larger groups (such as TSG response teams). Research by Janssens and Zanoni (2005) shows that the way in which work is organized strongly affects the discourse of diversity and employees' attitudes towards diversity management initiatives.

The dichotomy of diversity perspectives in the MPS supports the viewpoint of a discursive shift from equal opportunities to diversity management (Kelly and Dobbin, 1998; Litvin; 1997). This 'critical turning point' (Lorbiecki and Jack, 2000) towards a valuing diversity approach requires a shift in the practice of managing diversity in the organisation (Tatli, 2011).

\section{Discussion and Conclusion}

The analysis revealed three perspectives on workforce diversity: the access-and-legitimacy perspective and the integration-and-learning perspective, which correspond with existing theories (Ely and Thomas, 2001; Dass and Parker, 1999); a new dual perspective emerged in this study and is labelled as the dual access-and-learning perspective. The research findings illustrated that different perspectives are adopted by the different work groups and in 
different contexts of work, thereby demonstrating that the context and process of workforce diversity determines the discourse on diversity (Cavanaugh, 1997; Prasad, 1997; Johns, 2004; Janssens and Zanoni, 2005). The key influencing factors identified in this study include: socio-cultural background, team diversity, team structure and size, level of public and community interface, and organisational ethos.

The context of work plays an important role in the discourse of diversity which is functional in sustaining and reproducing the governing logic of diversity and the practice of managing diversity (Cavanaugh and Prasad, 1997; Johns, 2004; Janssens and Zanoni, 2005). A shared understanding of diversity can potentially amount to a powerful tool for managing diversity to attain organisational goals. A negotiated perspective comes about through the discourse of diversity which is entangled in the day-to-day processes of work. From this standpoint, discourses can be regarded as powerful resources (Fairclough, 2003), whereby different organisational actors construct different realities and negotiate their perspectives in relation to wider organisational practices. Fairclough (2003: 124) explains that "different discourses are different perspectives on the world, and they are associated with the different relations people have to the world, which in turn depends on their positions in the world, their social and personal identities, and the social relationships in which they stand to other people".

The results showed that the development of a shared understanding of diversity took place in the space of the day-to-day processes of police work. Janssens and Zanoni (2005) also show that the way in which work is organized strongly affects the organisation's understanding of diversity as well as its approach to diversity management. This study supported the viewpoint that the discourse of diversity is anchored in an organisation's productive logic (Janssens and Zanoni, 2005). Police officers, time after time, described their diversity in relation to its impact on their work outcomes. 


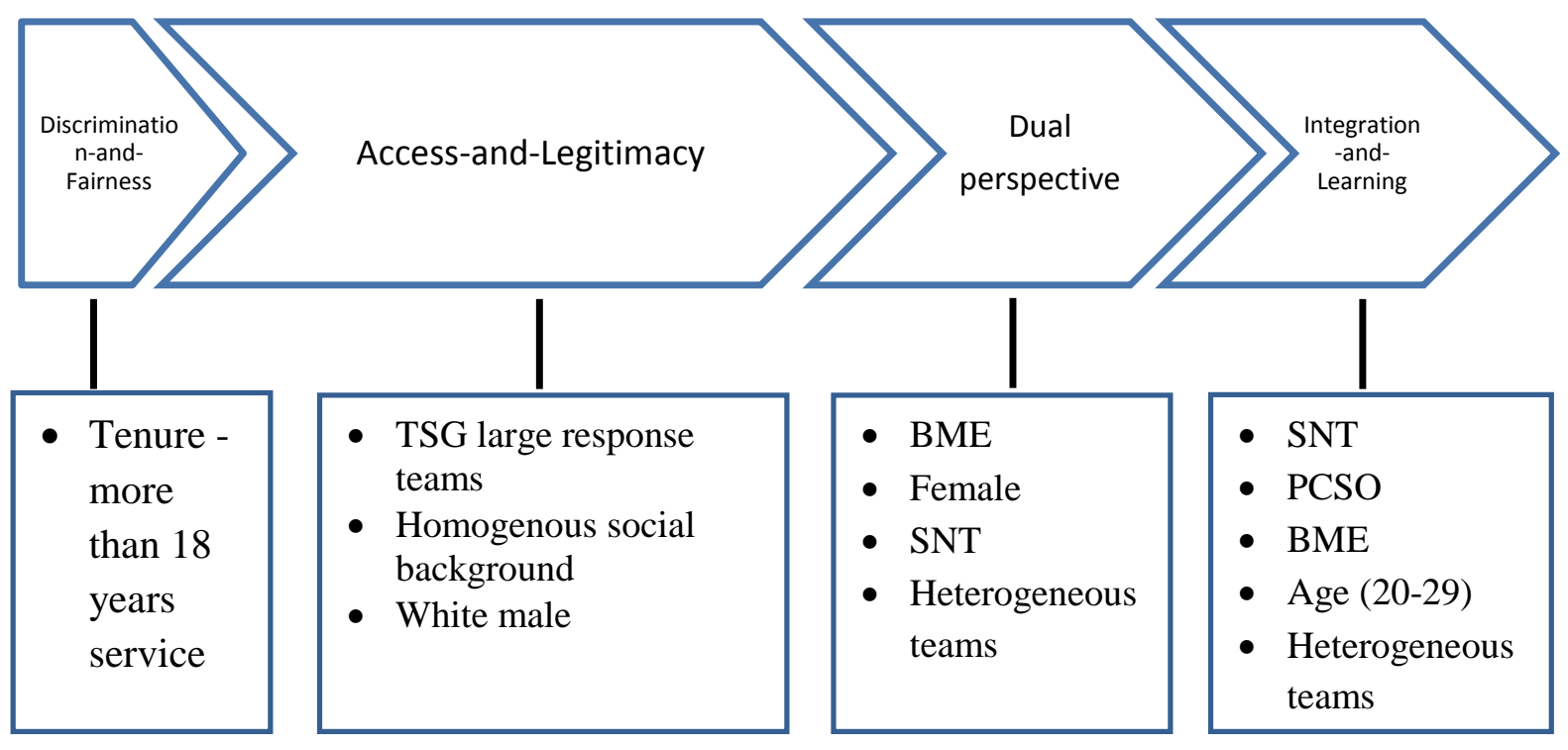

Figure 2 - The diversity perspectives of different identity categories.

Figure 2 shows the diversity perspectives expressed by the different categories of respondents. The key variables at the individual level include length of service (tenure), racio-ethnicity and age. White males predominantly expressed an access-and-legitimacy perspective, while BME officers either held an integration-and-learning perspective or expressed both access-and-legitimacy and integration-and-learning perspectives (dual accessand-learning). It is difficult to theorise this difference in perspectives between BME and white males because of the complex interaction of multiple identity dimensions within and between the identity groups. Studies with a deep intersectional analysis could explore this topic. However, evidence from heterogeneous teams in the MPS show that, as the workforce becomes more diverse, the social learning element of the integration-and-learning perspective is increasingly acknowledged in the organisation's discourse of diversity. Hence, the social embeddedness of diversity will continuously produce and reproduce the social fabric of the MPS, and thereby progressing the diversity discourse as the social context of work evolves. 
Respondents aged 20-29 predominantly expressed an integration-and-learning perspective, demonstrating alternative views to the espoused values and perspectives of the MPS. Older respondents, or those with more than 18 years' service, shared viewpoints aligned with the discrimination-and-fairness perspective, but tended to adopt a general access-and-legitimacy perspective on diversity. The age distinction in diversity perspective is a significant indication that the integration-and-learning perspective is being brought into the MPS by its new recruits. One could therefore conclude that the dual perspective is a manifestation of the natural employee progression that takes place in the MPS, and its diversity perspectives will transition concurrently with the progression of women and BME officers.

The dual diversity perspectives adopted in different parts of the police service demonstrate the persistent incoherence of certain organisational values and practices, which result in a multi-layered value system and a sedimented police archetype. The access-andlegitimacy perspective appears to be deeply institutionalised in the MPS. The integration-andlearning perspective is strongly manifested in some areas of the MPS (such as SNT) but its full development is impeded by a long-established and unyielding police archetype.

Deeply institutionalised archetypes are hard to change but they are subject to challenge, environmental pressures and consequent delegitimation (Brock, 2007; Cooper et al., 1996). Chan (1997 and 2003) contends that police culture is neither homogeneous nor immune to change. This study has shown that different perspectives on workforce diversity are adopted by different work groups, subcultures, in different contexts of work, and at different stages in an individual's career. The multiplicity of diversity perspectives depicts a form of sedimented change process in the MPS. This geological metaphor of sedimentation allows us to consider a dialectical rather than a linear view of change (Cooper et al; 1996). 
Sedimentation is merely the laying down of one archetype on top of another (Brock, Powell and Hinnings, 2007).

The transitional dual perspective illustrates the competing commitments of the structure and processes of policing. The MPS has already undergone some amount of archetype reconstruction with its shift from enforcement style policing to service oriented policing (Reuss-Ianni and Ianni, 1983). New soft skills are gaining more prominence as PCSOs and officers on SNT are perceived as mentors, facilitators, and not just combatants. The SNT and PCSO structure represents a new value system of the MPS, which mainly adopts an integration-and-learning perspective on diversity. However, this new structure and values coexist with the long-established police archetype. Sillince and Brown (2009) argue that this multiple identity constitutes part of constabularies' self-presentation strategies, by which they attempted to exert control over stakeholders' perceptions and establish pragmatic, cognitive and moral claims to legitimacy.

The findings indicate that a sole dominant integration-and-learning perspective might not be completely attainable in MPS, but could be achieved at levels in the organisation where there are subversive values and a contingent approach to managing diversity. Joshi and Roh (2009) called for a "contextual diagnosis" of workforce diversity to allow firms to develop practices that are tailored to reduce categorization-based processes and enhance elaboration-based processes at the team level. This study has delivered rich contextual analysis at the individual, team, and meso-level of the MPS. This context-based approach to researching workforce diversity has provided practical insights into the discourse of diversity. Foster and Harris (2005) urge employers to adopt a contextually informed and organisationally realistic view of diversity management. This research suggests that management should adopt a context-based approach to diversity management in order to build support in different parts of the organisation. The empirical evidence showed that the 
contextualized understandings of diversity in the MPS imposed a specific discourse of diversity which was plainly anchored in the unique contexts of policing (Janssens and Zanoni, 2005; Johns 2004).

The research findings have informed our understanding of the complex issues surrounding workforce diversity and demonstrate the value of operationalising the concept of diversity perspectives (Ely and Thomas, 2001; Dass and Parker, 1999). This study explored the experiences and processes of workforce diversity based on the perspectives of employees. The demonstration of an association between diversity perspectives and the social experiences of different identity groups is an important step in advancing research about cause and effect and also supporting real organisations in their effort to improve social relations and policy implementation in the workplace (Ozbilgin 2011; Zanoni 2010). The research found only two of the four theorised diversity perspectives being currently held in the MPS. However, the findings revealed a new dual perspective, taking values from the access-and-legitimacy and the integration-and-learning perspectives. The research also provided empirical evidence on how multiple organisational, societal, and individual factors can influence the diversity perspective of different groups of employees.

\section{References}

Acker, J. 2006. Inequality regimes: gender, class and race in organizations. Gender and Society, 20: 441-464.

Bendl, R., Fleischmann, A. and Walenta, C. 2008. Diversity management discourse meets queer theory. Gender in Management: An International Journal, 23 (6): 382-394.

Brown, J. 1998. Aspects of Discriminatory Treatment of Women Police Officers in Forces in England and Wales, British Journal of Criminology, 38: 265 - 82.

Brown, J. 2007. From cult of masculinity to smart macho: gender perspectives on police occupational culture, in Sklansky, D.A. (ed.), Police Occupational Culture (Sociology of Crime, Law and Deviance, Vol. 8), Emerald Group Publishing Limited: 205-226. 
Chan, J., Devery, C. and Doran, S. 2003. Fair cop: learning the art of policing. Toronto: University of Toronto Press.

Chow, I., Hau, S. and Crawford, R.B. 2004. Gender, ethnic diversity, and career advancement in the workplace: the social identity perspective. SAM Advanced Management Journal, 69 (3): $22-31$.

Cordero, R., DiTomaso, N. and Farris, G. F. 1997. Gender and race/ethnic composition of technical work groups: relationship to creative productivity and morale. Journal of Engineering and Technology Management 13: 205-221.

Dass, P. and Parker, B. 1999. Strategies for managing human resource diversity: from resistance to learning. The Academy of Management Executive, 13 (2): 68-80.

Davies, A. and Thomas, R. 2008. Dixon of dock green got shot! Policing identity work and organizational change. Public Administration, 86 (3): 627-642.

Dick, P. and Jankowicz, D. 2001. A social constructionist account of police culture and its influence on the representation and progression of female officers: a repertory grid analysis in a UK police force. Policing: An International Journal of Police Strategies \& Management, 24 (2): 181-199.

Doran, S. and Chan, J. 2003. Doing gender, in Chan, J. with Devery, C. and Doran, S., Fair Cop: Learning the Art of Policing. Toronto: University of Toronto Press: 276-300.

Ely, R. 1995. The power in demography: women's social construction of gender identity at work. Academy of Management Journal, 38 (3): 589-634.

Ely, R.J. and Thomas, D.A. 2001. Cultural diversity at work: The effects of diversity perspectives on work group processes and outcomes. Administrative Science Quarterly, 46 (2): 229-273.

Fielding, N. 1994. Cop canteen culture, in Newburn, T. and Stanko, E.A. (eds.), Just Boys Doing Business: Men, Masculinities and Crime. London: Routledge.

Gerber, G.L. 2001. Women and men police officers: status, gender, and personality. Greenwood Press.

He, N.; Zhao, J. and Archbold, C.A. 2002. Gender and police stress: The convergent and divergent impact of work environment, work-family conflict, and stress coping mechanisms of female and male police officers. Policing, 25: 687-707. 
Iles, P., Wilson, E. and Hicks-Clarke, D. 1998. Diversity climates and gendered cultures: a cross sector analysis, in C. Mabey, D. Skinner and T. Clark (eds), Experiencing Human Resource Management, London: Sage.

Itzin, C. 1995b. Gender, culture, power and change: a materialist analysis, in Itzini C. and Newman, J. (eds.), Gender, Culture and Organizational Change: Putting Theory into Practice, London, New York: Routledge: 246-272.

Janssens, M. and Zanoni, P. 2005. Many Diversities for Many Services: Theorizing Diversity (Management) in Service Companies. Human Relations, 58(3): 311-40.

Joshi, A. and Roh, H. 2009. The Role of context in work team diversity research: a metaanalytic review. Academy of Management Journal, 52 (3): 599-627.

Kulik, C. T. 2014. Working Below and Above the Line: The Research-Practice Gap in Diversity Management. Human Resource Management Journal, 24: 129-144.

Leishman, F., Loveday, B. and Savage, S. 2000. Core issues in policing. Pearson: England.

Litvin, D.R. 1997. The discourse of diversity: From biology to management. Organization, 4(2): 187-209.

Martin, S.E. 1980. Breaking and entering: policewomen on patrol. Berkeley, CA: University of California Press.

Martin, S.E. 1999. Police force or police service? Gender and emotional labor. The Annals of the American Academy of Political and Social Science, 561 (1): 111-126.

Martin, S.E. and Jurik, N.C. 2006. Doing justice, doing gender: women in legal and criminal justice occupations. Los Angeles, CA: Sage.

Maxwell, G.A., Blair, S., and McDougall, M. 2001. Edging towards managing diversity in practice. Employee Relations, 23 (5): 468-482.

Mor Barak, E.M. 2000. The inclusive workplace: an ecosystems approach to diversity management. Social Work, 45 (4): 339-352.

Mor Barak, M.E. 2005. Managing Diversity: Toward A Globally Inclusive Workplace. London: SAGE Publications.

Mor Barak, M.E., Cherin, D.A. and Berkman, S. 1998. Organizational and Personal Dimensions in Diversity Climate: Ethnic and Gender Differences in Employee Perceptions. The Journal of Applied Behavioral Science, 34: 82-104. 
Rabe-Hemp, C. 2009. 'POLICEwomen or PoliceWOMEN? Doing Gender and Police Work. Feminist Criminology, 4 (2): 114-129.

Silvestri, M. 2003. Women in Charge: Policing, Gender and Leadership. Willan: Cullompton.

Smith, D. J. and Gray, J. 1985. Police and People in London: The PSI Report. London: Policy Studies Institute.

Steinbugler, A.C., Press, J.E. and Dias, J.J. 2006. Gender, race, and affirmative action: operationalizing intersectionality in survey research. Gender and Society, 20: 805-825.

Tatli, A., Ozbilgin, M. and Ktiskil, F. 2008. Gendered occupational outcomes: the case of professional training and work in Turkey, in Eccles, J. and Watt, H. (eds.), Explaining Gendered Occupational Outcomes. Michigan: American Psychological Association Press.

Thomas, R.R. 1991. Beyond race and gender. New York: AMACOM.

Truss, C. 1999. Human resource management: gendered terrain? The International Journal of Human Resource Management, 10 (2): 180-200.

Waddington, P.A.J. 1999. Police (canteen) sub-culture: an appreciation. British Journal of Criminology, 39 (2): 287-309.

Walklate, S. 2000. Equal opportunities and the future of policing, in: Leishman, F., Loveday, B. and Savage, S. (eds.) Core Issues in Policing, (2nd edition). Essex: Pearson Education Ltd.

Ward, J. 2004. Not all differences are created equal: multiple jeopardy in a gendered organization. Gender \& Society, 18(1): 82-102.

West, C. and Zimmerman, D.H. 1987. Doing Gender. Gender \& Society, 1 (2): 125-151.

West, C. and Zimmerman, D.H. 2002. Doing Gender, in West, C. and Fenstermaker, S. (eds.), Doing Gender, Doing Difference: Inequality Power and Institutional Change. New York: Routledge: 3-24.

Westmarland, L. 2001. Gender and policing: sex, power and police culture. Cullompton: Willan. 
Yuval-Davis, Nira 2005. Gender mainstreaming and intersectionality, Swedish Journal of Women's Studies (Kvino-vetenskaplig tidskrift), special issue on 'Inter- sectionality' 2-3, 1929.

Zanoni, P. and Janssens, M. 2003. Deconstructing difference: the rhetoric of human resource managers' diversity discourses. Organisation Studies, 25 (1): 55-74.

Zanoni, P. and Janssens, M. 2007. Minority Employees Engaging with (Diversity) Management: An Analysis of Control, Agency, and Micro-Emancipation. Journal of Management Studies, 44: 1371-1397. 